\title{
Tuberculosis: still an enigma. Presenting as mycotic aneurysm of aorta
}

\author{
Vikram B Kolhari, Shivakumar Bhairappa, Prasad N M, C N Manjunath
}

Department of Cardiology, Sri Jayadeva Institute of Cardiovascular Sciences and Research, Bangalore, Karnataka, India

Correspondence to Dr Shivakumar Bhairappa, snbhairappa@gmail.com

\footnotetext{
To cite: Kolhari $V B$, Bhairappa S, N M P, et al. BMJ Case Rep Published online: [please include Day Month Year] doi:10.1136/ bcr-2013-008869
}

The term mycotic aneurysm is a misnomer that has nevertheless been generally adopted to describe aneurysms that occur secondary to the infectious destruction of the arterial wall. Mycotic aneurysm secondary to tuberculous infection of the aorta is a rare and life-threatening disease. Both abdominal and thoracic aorta are involved with equal frequency. ${ }^{1}$ Tuberculous aneurysms are usually a consequence of transmural perforation caused by direct extension to the vessel from a contiguous focus, often lymphadenitis, but also pulmonary, ${ }^{2}$ digestive or vertebral. Other mechanisms implicated are haematogenous contamination through the vasa vasorum, ${ }^{3}$ or an autoimmune response to tuberculosis.

Clinical features are highly variable, ranging from asymptomatic aneurysm with or without constitutional symptoms, pulsatile or palpable mass, chest pain, dysphagia, hoarseness, abdominal pain, back pain, to frank rupture, bleeding and shock. The key to the diagnosis is a high index of suspicion.

A 55-year-old man with prior exposure to tuberculosis, presented with low-grade fever, loss of appetite, significant weight loss and vague and atypical chest pain of 3 months duration. Investigations revealed lymphocytosis, raised erythrocyte sedimentation rate $(94 \mathrm{~mm}$ for the first hour) and a positive Mantoux test.

Chest x-ray showed multiple, enlarged hilar lymph nodes and a widened mediastinum. Two-dimensional echocardiography showed a dilated descending thoracic aorta compressing the left atrium (figure 1A,B; online videos 1-3). CT of the thorax confirmed multiple, enlarged hilar and mediastinal lymph nodes with central caseation (figure 2A) and a $6.5 \times 6 \mathrm{~cm}$ saccular aneurysm involving the descending thoracic aorta (D6 and D7 level), with thin peripheral intraluminal thrombus (figure 2C,D). There was also evidence of an aneurysm of the left circumflex (LCX) coronary artery which was seen also on echocardiography (figures 1 and 2B).

The patient underwent surgery and biopsy and confirmed the diagnosis. He was started on fourdrug antituberculous regimen and is doing well at 1 year follow-up. The index case highlights the importance of timely surgery. Whether the LCX aneurysm was secondary to tuberculosis could be debated.
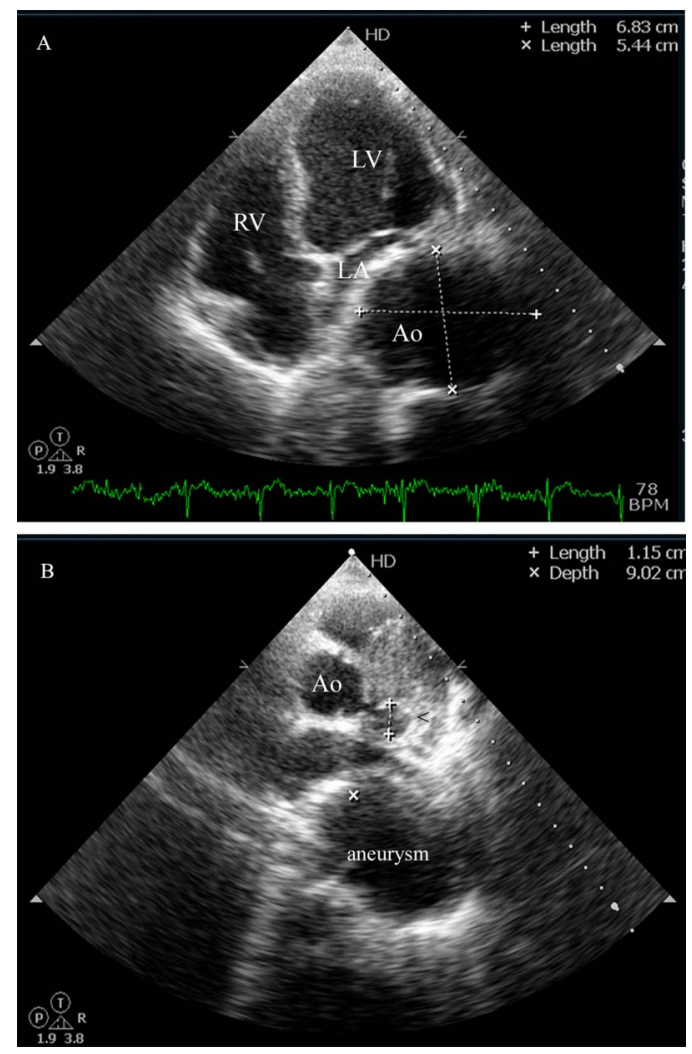

Figure 1 (A) Apical four chamber view showing a large aortic aneurysm compressing the left atrium. (B) Parasternal short axis view showing aneurysmal dilation of the left coronary artery.

\section{Learning points}

Symptomatic tubercular mycotic aneurysm is an extremely rare but uniformly fatal lesion if not diagnosed promptly. High index of suspicion is the key.

- Clinical presentation can be highly variable, ranging from asymptomatic state, vague chest pain, constitutional symptoms to hypovolemic shock and death.

- Combined medical and surgical therapies offer the best chance for a cure. Medical therapy alone is ineffective. 
Figure 2 (A) CT of the thorax showing enlarged mediastinal lymph node with central caseation. (B) CT of the thorax showing the left circumflex coronary artery aneurysm.

(C) Three-dimensional reconstructed CT image showing aneurysm of the descending aorta. (D) CT of an aortogram showing saccular aneurysm of the descending thoracic aorta (D6 and D7 level), with thin peripheral intraluminal thrombus.
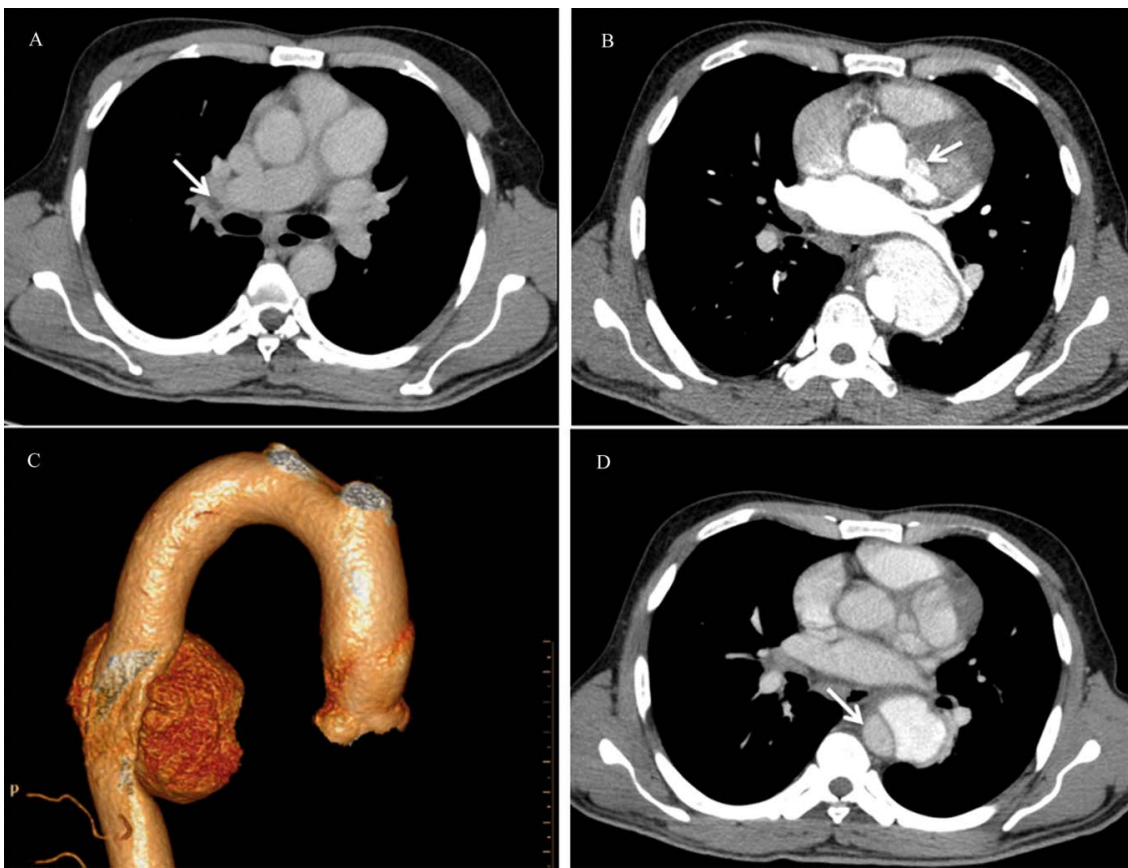

Contributors $S B, V B K$ and PNM were directly involved in the patient management conceptualised and approved the final manuscript. VBK drafted the manuscript. CNM critically reviewed the manuscript for intellectual content.

Competing interests None.

Patient consent Obtained.

Provenance and peer review Not commissioned; externally peer reviewed.

\section{REFERENCES}

1 Munyer TP, Margulis AR. Tuberculous aortitis. AJR Am J Roentgenol 1981;136:1024-6.

2 Hara M, Bransford RM. Aneurysm of the subclavian artery associated with contiguous pulmonary tuberculosis. J Thorac Cardiovasc Surg 1963;46:256-64.

3 Long R, Guzman R, Greenberg H. Tuberculous mycotic aneurysm of the aorta: review of published medical and surgical experience. Chest 1999;115:522-31.

Copyright 2013 BMJ Publishing Group. All rights reserved. For permission to reuse any of this content visit

http://group.bmj.com/group/rights-licensing/permissions.

BMJ Case Report Fellows may re-use this article for personal use and teaching without any further permission.

Become a Fellow of BMJ Case Reports today and you can:

- Submit as many cases as you like

- Enjoy fast sympathetic peer review and rapid publication of accepted articles

- Access all the published articles

- Re-use any of the published material for personal use and teaching without further permission

For information on Institutional Fellowships contact consortiasales@bmjgroup.com

Visit casereports.bmj.com for more articles like this and to become a Fellow 